\title{
Visceral Adiposity Index is Associated With Silent Brain Infarct in a Healthy Population
}

\section{Ki-Woong Nam}

Departments of Neurology https://orcid.org/0000-0001-7514-6264

\section{Hyung-Min Kwon ( $\nabla$ hmkwon@snu.ac.kr)}

Department of Neurology

\section{Han-Yeong Jeong}

Departments of Neurology

\section{Jin-Ho Park}

3Family Medicine, Seoul National University College of Medicine and Seoul National University Hospital, Seoul, Korea

\section{Hyuktae Kwon}

3Family Medicine, Seoul National University College of Medicine and Seoul National University Hospital, Seoul, Korea

\section{Su-Min Jeong}

Family Medicine, Seoul National University College of Medicine and Seoul Metropolitan GovernmentSeoul National University Boramae Medical Center, Seoul, Korea

\section{Original investigation}

Keywords: Adipose tissue, Cerebrovascular disease, Obesity, Silent brain infarct, Small vessel disease

Posted Date: August 4th, 2020

DOI: https://doi.org/10.21203/rs.3.rs-48853/v1

License: (c) (1) This work is licensed under a Creative Commons Attribution 4.0 International License. Read Full License

Version of Record: A version of this preprint was published at Scientific Reports on October 14th, 2020. See the published version at https://doi.org/10.1038/s41598-020-74454-6. 


\section{Abstract \\ Background}

Visceral adiposity index (VAI) is a novel indicator of the mass and function of visceral adipose tissue, and it has been associated with metabolic disease, cardiovascular disease, and subclinical atherosclerosis; however, there is limited information about its association with cerebrovascular diseases, especially in subclinical pathology. In this study, we evaluated the relationship between VAl and silent brain infarct $(\mathrm{SBI})$ in a healthy population.

\section{Methods}

We evaluated a consecutive series of healthy volunteers over the age of 40 between January 2006 and December 2013. SBI was defined as an asymptomatic, well-defined lesion with a diameter $\geq 3 \mathrm{~mm}$ with the same signal characteristics as the cerebrospinal fluid on T1- or T2 weighted images. VAI was calculated using sex-specific equations as described in previous studies, and was based on a number of parameters including waist circumference, triglycerides, high-density lipoprotein cholesterol, and body mass index.

\section{Results}

A total of 2,596 subjects were evaluated (mean age 56y, male sex: $54 \%$ ), and SBI was found in 218 (8\%) participants. In multivariable analysis, VAI (adjusted odds ratio $[\mathrm{aOR}]=1.30 ; 95 \%$ confidence interval $[\mathrm{Cl}]=$ 1.03-1.66; $P=0.030$ ) remained a significant predictor of $\mathrm{SBI}$ after adjustment for confounders. On the other hand, visceral adipose tissue area on computed tomography did not show any statistical significance with SBI. The close relationship between VAI and SBI was prominent only in females (aOR = $1.44 ; 95 \% \mathrm{Cl}=1.00-2.07 ; P=0.048)$. In the evaluation between VAI and the burden of SBI, VAI showed a positive dose-response relationship with the number of SBI lesions ( $P$ for trend $=0.037$ ).

\section{Conclusions}

High VAI was associated with a higher prevalence and burden of SBI in a neurologically healthy population, especially in females. Our findings indicate that VAI could be used as a simple and convenient predictor for SBI.

\section{Introduction}

Global obesity rates are currently increasing,[1] leading to serious health complications worldwide that include cardio/cerebrovascular diseases, atherosclerosis, and subclinical inflammation.[1, 2] However, such obesity-related complications do not occur in all obese patients and vary depending on individual 
characteristics. $[3,4]$ In recent years, it has been recognized that the distribution of fat plays a substantially more important role in obesity-related complications than dose the amount of total fat.[5-7] Visceral adipose tissue (VAT) has been shown to be associated with the risk of insulin resistance and cardio/cerebrovascular disease, $[6,8,9]$ whereas subcutaneous adipose tissue (SAT) appears to be less influential and even rather protective. $[6,10]$ Therefore, instead of using the traditional body mass index (BMI), various indicators reflecting fat distribution differences across individuals have been developed and used.

For accurate measurements of the distribution and amount of fat, imaging modalities such as magnetic resonance imaging (MRI) and computed tomography (CT) have been used.[11, 12] However, as shown in recent studies on "metabolically healthy obesity", in addition to problems with quantity of adipose tissue, functional aspects such as the presence of accompanying metabolic diseases must be considered.[1, 4] On this theoretical basis, Amato et al. developed a sex-specific index for predicting VAT mass and function using waist circumference (WC), BMI, triglyceride (TG), and high-density lipoprotein (HDL) cholesterol.[8] This visceral adiposity index (VAl) was closely associated with metabolic disease, cardiovascular disease, and even atherosclerosis.[10-14] However, studies on cerebrovascular disease is still lacking.

Silent brain infarct (SBI) is a subclinical pathological condition that is commonly found in elderly individuals. $[15,16] \mathrm{SBI}$ itself is asymptomatic but increases the risk of subsequent strokes.[16] Therefore, a clear understanding of the pathological mechanisms and risk factors of SBI may be helpful in the primary prevention of cerebrovascular disease in the subclinical stage. In this study, we evaluated the relationship between VAI and SBI in a neurologically healthy population to gain insight into underlying pathological mechanisms.

\section{Methods}

\section{Patients and population}

From a consecutive registry of health check-ups at Seoul National University Hospital Health Promotion Center between January 2006 and December 2013, we retrospectively included subjects over the age of 40 years $(n=2,904)$. Among them, 49 participants who had a history of stroke or clinically meaningful neurological deficit were excluded. Participants using lipid lowering agents $(n=219)$ and having missing data regarding covariates $(n=40)$ were also excluded. Finally, a total of 2,596 neurologically healthy participants were included in the final cross-sectional analyses. This study was approved by the Institutional Review Board (IRB No.: H-1502-026-647) at Seoul National University Hospital. Requirement of informed consent from participants was waived by the IRB due to the retrospective study design using anonymized information. Any data not published within the article are available from the corresponding author upon reasonable request.

\section{Clinical assessment}


As part of routine health check-ups, we evaluated demographic factors, clinical factors, and cardiovascular risk factors in all participants. Age, sex, BMI, hypertension, diabetes, ischemic heart disease, current smoking, use of medications (e.g., antiplatelet agents, antihypertensives, and glucose lowering agents), systolic and diastolic blood pressure (BP) were assessed.[4, 6] Laboratory examinations were conducted after 12 hours overnight fasting, including glucose profiles, lipid profiles, white blood cell (WBC) counts, high-sensitivity C-reactive protein (hs-CRP) and homocysteine levels.[4, 6]

The VAI was calculated using the sex-specific equations as described in previous studies: VAI = $[\mathrm{WC} /(39.68+1.88 \times \mathrm{BMI})] \times(\mathrm{TG} / 1.03) \times(1.31 / \mathrm{HDL}$ cholesterol $)$ for males and $\mathrm{VAl}=[\mathrm{WC} /(36.58+1.89 \times$ $\mathrm{BMI})] \times(\mathrm{TG} / 0.81) \times(1.52 / \mathrm{HDL}$ cholesterol) for females.[8]

\section{Radiological assessment}

All participants underwent brain MRI using 1.5-T MR scanners (SIGNA [GE Healthcare, Milwaukee, WI, USA] or Magnetom SONATA [Siemens, Munich, Germany]). The detailed descriptions of MRI acquisitions were as follows: basic slice thickness, $5 \mathrm{~mm}$; T1-weighted images, repetition time (TR)/echo time (TE) = 500/11 ms; T2-weighted images, TR/TE = 5000/127 ms; T2-gradient echo images, TR/TE = 57/20 ms; and T2 fluid-attenuated inversion recovery images, TR/TE $=8800 / 127 \mathrm{~ms}$. SBI was defined as asymptomatic, well-defined lesions, $>3 \mathrm{~mm}$ in size with the same signal characteristics as cerebrospinal fluid on T1 and T2 images.[4, 15] We also rated the burden of SBI as absent, single, or multiple, based on their number.[4]

In this dataset, most participants $(n=2,136)$ conducted abdominal fat CT scans using a 16-detector row CT scanner (Somatom Sensation 16, Siemens Medical Solutions, Forchheim, Germany).[6] To obtain the adipose tissue area, we used a technique that we have previously validated.[6] We first obtained a single slice at the umbilicus level at $5 \mathrm{~mm}$ thickness with a scan time of $0.5 \mathrm{sec}$. Then, we calculated the crosssectional surface area (in $\mathrm{cm}^{2}$ ) of the different abdominal compartment using commercially available CT software (Rapidia 2.8; INFINITT, Seoul, Korea).[6] The adipose tissue area was determined electronically using the setting of attenuation levels from -250 to -50 Hounsfield units. VAT was identified as the intraabdominal fat that was surrounded by the parietal peritoneum or transversalis fascia, and excluding the vertebral column and paraspinal muscles. SAT was calculated by subtracting the VAT from the total adipose tissue (TAT) area.[6]

\section{Statistical analysis}

We performed all statistical analyses using SPSS version21.0 (IBM SPSS, Chicago, IL, USA). Univariate analyses for assessing possible predictors for SBI were performed using Student's $t$-test or Mann-Whitney $u$-test for continuous variables and Chi-squared test or Fisher's exact test for categorical variables.

Variables with severely skewed data were transformed into a log scale. Based on the results of univariate analysis, variables with $P<0.10$ were introduced into the multivariable logistic regression analysis. We wondered how the VAI was related to the burden as well as to the prevalence of $\mathrm{SBI}$, and compared the median VAI values according to the SBI burden using the Jonckheere-Terpstra test ( $P$ for trend.). In 
addition, we conducted additional sensitivity analyses to compare the predictive power between VAI and VAT on fat CT.

Males and females differ in composition of VAT and SAT.[6] Thus, VAI was formulated differently for males and females in consideration of sex differences.[8] Nevertheless, previous studies have shown that VAl is more influential in females. $[13,17,18]$ We, therefore, conducted a stratified multivariable analysis by sex to confirm these results. All variables with $P<0.05$ were considered significant in this study.

\section{Results}

A total of 2,596 neurologically healthy participants (mean age $56 \pm 7$ years, male sex: $54 \%$ ) were included. SBI was found in $218(8 \%)$ participants, and the mean VAI was $1.66 \pm 1.33$. Other detailed baseline characteristics are presented in Additional file 1: Table S1.

Univariate analysis showed that SBI was significantly associated with age, hypertension, diabetes, use of antiplatelet agents and antihypertensives, systolic and diastolic BP, hemoglobin A1c level, VAT, TAT, and VAI (Table 1). In a multivariable logistic regression analysis to find possible predictors for SBI, VAI remained significant after adjusting for confounders [adjusted odds ratio $(\mathrm{aOR})=1.30 ; 95 \%$ confidence interval $(\mathrm{Cl})=1.03-1.66 ; P=0.030$ ]. Age and hypertension were also positively associated with $\mathrm{SBI}$, independent of VAI (Table 2). VAl even showed a dose-response relationship according to the number of SBI lesions ( $P$ for trend $=0.037$ ) (Fig. 1$)$. On the other hand, VAT did not show any statistically significant association with SBI $(P=0.121)$ (Table 2$)$. 
Table 1

Univariate analysis between with $\mathrm{SBI}$ and without SBI groups.

\begin{tabular}{|c|c|c|c|}
\hline & $\begin{array}{l}\text { No SBI } \\
(n=2,408)\end{array}$ & $\begin{array}{l}\text { SBI } \\
(n=188)\end{array}$ & $P$ value \\
\hline Age, $\mathrm{n}(\%)$ & & & $<0.001$ \\
\hline$<55 y$ & $1,115(46)$ & $36(19)$ & \\
\hline $55-64 y$ & $1,014(42)$ & $86(46)$ & \\
\hline$\geq 65 y$ & $279(12)$ & $66(35)$ & \\
\hline Sex, male, n (\%) & $1,301(54)$ & $99(53)$ & 0.717 \\
\hline Body mass index, $\mathrm{kg} / \mathrm{m}^{2}[\mathrm{IQR}]$ & $23.95[22.16-25.83]$ & 23.97 [22.04-26.03] & 0.642 \\
\hline Hypertension, n (\%) & $504(21)$ & $67(36)$ & $<0.001$ \\
\hline Diabetes, n (\%) & $312(13)$ & $39(21)$ & 0.002 \\
\hline Ischemic heart disease, $\mathrm{n}(\%)$ & $67(3)$ & $5(3)$ & 0.921 \\
\hline Current smoking, n (\%) & $438(18)$ & $31(16)$ & 0.560 \\
\hline Use of antiplatelet agents, n (\%) & $189(8)$ & $26(14)$ & 0.004 \\
\hline Use of antihypertensives, n (\%) & $431(18)$ & $56(30)$ & $<0.001$ \\
\hline $\begin{array}{l}\text { Use of glucose-lowering agents, } n \\
(\%)\end{array}$ & $122(5)$ & $12(6)$ & 0.432 \\
\hline Systolic BP, mmHg [IQR] & $125[115-136]$ & $131[120-142]$ & $<0.001$ \\
\hline Diastolic BP, mmHg [IQR] & 75 [69-83] & 78 [72-87] & $<0.001$ \\
\hline Hemoglobin A1c, \% [IQR] & $5.7[5.5-6.0]$ & $5.9[5.5-6.2]$ & $<0.001$ \\
\hline Fasting glucose, mmol/L [IQR] & $5.01[4.62-5.50]$ & $5.06[4.68-5.94]$ & 0.058 \\
\hline Total cholesterol, mmol/L [SD] & $5.23 \pm 0.92$ & $5.14 \pm 0.94$ & 0.139 \\
\hline LDL cholesterol, mmol/L [IQR] & $3.34[2.74-3.88]$ & $3.21[2.53-3.98]$ & 0.352 \\
\hline HDL cholesterol, mmol/L [IQR] & $1.38[1.17-1.64]$ & $1.33[1.14-1.57]$ & 0.151 \\
\hline Triglyceride, mmol/L [IQR] & $1.11[0.82-1.62]$ & $1.18[0.86-1.68]$ & 0.147 \\
\hline White blood cell, $\times 10^{3} / \mu \mathrm{L}[\mathrm{IQR}]$ & $5.24[4.34-6.30]$ & $5.35[4.34-6.30]$ & 0.367 \\
\hline \multicolumn{4}{|c|}{$\begin{array}{l}\mathrm{SBI}=\text { silent brain infarct, } \mathrm{BP}=\text { blood pressure, } \mathrm{LDL}=\text { low-density lipoprotein, } \mathrm{HDL}=\text { high-density } \\
\text { lipoprotein, hs-CRP = high-sensitivity } \mathrm{C} \text {-reactive protein, VAT = visceral adipose tissue, SAT = } \\
\text { subcutaneous adipose tissue, } \mathrm{TAT}=\text { total adipose tissue }\end{array}$} \\
\hline \multicolumn{4}{|c|}{ *These variables were measured in 2,136 participants } \\
\hline
\end{tabular}




\begin{tabular}{|c|c|c|c|}
\hline & $\begin{array}{l}\text { No SBI } \\
(n=2,408)\end{array}$ & $\begin{array}{l}\text { SBI } \\
(n=188)\end{array}$ & $P$ value \\
\hline hs-CRP, mg/dL [IQR] & $0.04[0.01-0.15]$ & $0.06[0.01-0.17]$ & 0.262 \\
\hline Homocysteine, $\mu \mathrm{mol} / \mathrm{L}$ [IQR] & $9.5[8.1-11.5]$ & $9.6[8.1-11.8]$ & 0.919 \\
\hline VAT, $\mathrm{cm}^{2}[\mathrm{IQR}]^{*}$ & 106.87 [72.99-148.74] & 121.25 [82.86-161.59] & 0.008 \\
\hline SAT, $\mathrm{cm}^{2}[\mathrm{IQR}]^{*}$ & $\begin{array}{l}150.59 \text { [114.56- } \\
196.01]\end{array}$ & 149.23 [118.29-201.53] & 0.332 \\
\hline $\mathrm{TAT}, \mathrm{cm}^{2}[\mathrm{IQR}]^{*}$ & $\begin{array}{l}265.37 \text { [206.67- } \\
332.56]\end{array}$ & $\begin{array}{l}284.11[223.61- \\
340.70]\end{array}$ & 0.035 \\
\hline Visceral adiposity index, [IQR] & $1.26[0.84-2.01]$ & $1.44[0.90-2.31]$ & 0.037 \\
\hline \multicolumn{4}{|c|}{$\begin{array}{l}\mathrm{SBI}=\text { silent brain infarct, } \mathrm{BP}=\text { blood pressure, } \mathrm{LDL}=\text { low-density lipoprotein, } \mathrm{HDL}=\text { high-density } \\
\text { lipoprotein, hs-CRP = high-sensitivity } \mathrm{C} \text {-reactive protein, VAT = visceral adipose tissue, } \mathrm{SAT}= \\
\text { subcutaneous adipose tissue, } \mathrm{TAT}=\text { total adipose tissue }\end{array}$} \\
\hline
\end{tabular}


Table 2

Multivariable logistic regression analysis of possible predictors for silent brain infarct

Crude OR

$(95 \% \mathrm{Cl})$
$P$-value Adjusted OR

$(95 \% \mathrm{Cl})$

Model $1(n=2,596)^{\dagger}$

Age

$<55 y$

Ref

Ref

Ref

Ref

$55-64 y$

2.63 [1.76-3.91]

$<0.001$

2.45 [1.64-3.67]

$<0.001$

$\geq 65 y$

7.33 [4.78-11.23]

$<0.001$

6.38 [4.11-9.92]

$<0.001$

Male sex

0.95 [0.70-1.27]

0.717

0.96 [0.70-1.30]

0.779

Hypertension

2.09 [1.53-2.86]

$<0.001$

1.52 [1.09-2.13]

0.015

Diabetes

1.77 [1.22-2.57]

0.003

$1.19[0.80-1.76]$

0.397

Use of antiplatelet agents

1.88 [1.21-2.93]

0.005

1.21 [0.76-1.93]

0.424

Visceral adiposity index*

1.30 [1.04-1.63]

0.022

1.30 [1.03-1.66]

0.030

Model $2(n=2,136)^{\ddagger}$

Age

$<55 y$

Ref

Ref

Ref

Ref

55-64y

2.63 [1.76-3.91]

$<0.001$

2.49 [1.63-3.81]

$<0.001$

$\geq 65 y$

7.33 [4.78-11.23]

$<0.001$

5.69 [3.55-9.10]

$<0.001$

Male sex

0.95 [0.70-1.27]

0.717

0.77 [0.55-1.09]

0.139

Hypertension

2.09 [1.53-2.86]

$<0.001$

1.70 [1.19-2.42]

0.004

Diabetes

1.77 [1.22-2.57]

0.003

1.21 [0.80-1.83]

0.372

Use of antiplatelet agents

$1.88[1.21-2.93]$

0.005

$1.06[0.62-1.81]$

0.831

Visceral adipose tissue ${ }^{*}$

1.49 [1.12-1.98]

0.006

$1.29[0.94-1.77]$

0.121

*These variables were transformed into a log scale.

${ }^{\dagger}$ Adjusted with $P<0.10$ in univariate analysis (age, male sex, hypertension, diabetes, use of antiplatelet agents, and visceral adiposity index).

FIncluded visceral adipose tissue instead of visceral adiposity index with Model 1. 
The close relationship between VAI and SBI was prominent only in females, both in their prevalence (aOR $=1.44 ; 95 \% \mathrm{Cl}=1.00-2.07, P=0.048)$ and burden ( $P$ for trend $=0.009)$ (Table 3 and Fig. 1$)$. Meanwhile, no statistical significance was found in male participants. These sex differences can be interpreted based on the results shown in Table 4. For most risk factors, similar results were found between male and female participants, but VAI was more strongly associated with hypertension or diabetes in female participants. Notably, males had a negative correlation between VAl and age, whereas females had a positive correlation (Table 4).

Table 3

Multivariable logistic regression analysis of the possible predictors for silent brain infarct stratified by sex

\begin{tabular}{|c|c|c|c|c|}
\hline & Male & & Female & \\
\hline & $\begin{array}{l}\text { Adjusted OR } \\
(95 \% \mathrm{Cl})\end{array}$ & $P$-value & $\begin{array}{l}\text { Adjusted OR } \\
(95 \% \mathrm{Cl})\end{array}$ & $P$-value \\
\hline \multicolumn{5}{|l|}{ Age } \\
\hline$<55 y$ & Ref & Ref & Ref & Ref \\
\hline $55-64 y$ & $2.19[1.28-3.73]$ & 0.004 & $2.76[1.47-5.18]$ & 0.002 \\
\hline$\geq 65 y$ & $4.86[2.68-8.81]$ & $<0.001$ & $8.70[4.42-17.15]$ & $<0.001$ \\
\hline Hypertension & $1.90[1.23-2.96]$ & 0.004 & $1.12[0.65-1.91]$ & 0.688 \\
\hline Diabetes & $1.06[0.63-1.77]$ & 0.835 & $1.49[0.80-2.75]$ & 0.206 \\
\hline Use of antiplatelet agents & $1.61[0.93-2.79]$ & 0.092 & $0.67[0.27-1.69]$ & 0.397 \\
\hline Visceral adiposity index ${ }^{*}$ & $1.17[0.85-1.61]$ & 0.350 & $1.44[1.00-2.07]$ & 0.048 \\
\hline
\end{tabular}


Table 4

Univariate linear regression analysis between visceral adiposity index ${ }^{*}$ and risk factors

\begin{tabular}{|c|c|c|c|}
\hline & Total & Male & Female \\
\hline & $\beta(95 \% \mathrm{Cl})$ & $\beta(95 \% \mathrm{Cl})$ & $\beta(95 \% \mathrm{Cl})$ \\
\hline \multicolumn{4}{|l|}{ Age } \\
\hline$<55 y$ & Ref & Ref & Ref \\
\hline $55-64 y$ & $\begin{array}{l}-0.049(-0.102 \text { to } \\
0.005)\end{array}$ & $\begin{array}{l}-0.159(-0.235 \text { to } \\
-0.084)\end{array}$ & 0.080 (0.006 to 0.154$)$ \\
\hline$\geq 65 y$ & $\begin{array}{l}-0.032(-0.109 \text { to } \\
0.046)\end{array}$ & $\begin{array}{l}-0.213(-0.322 \text { to } \\
-0.104)\end{array}$ & 0.188 (0.079 to 0.297$)$ \\
\hline Male sex & $\begin{array}{l}-0.027(-0.077 \text { to } \\
0.022)\end{array}$ & $\ldots$ & $\ldots$ \\
\hline Hypertension & 0.128 (0.068 to 0.187$)$ & 0.101 (0.019 to 0.183$)$ & $0.173(0.085$ to 0.261$)$ \\
\hline Diabetes & 0.206 (0.133 to 0.278$)$ & $0.170(0.076$ to 0.264$)$ & 0.293 (0.177 to 0.410$)$ \\
\hline $\begin{array}{l}\text { Ischemic heart } \\
\text { disease }\end{array}$ & $\begin{array}{l}-0.028(-0.180 \text { to } \\
0.123)\end{array}$ & $-0.112(-0.317$ to 0.094$)$ & $\begin{array}{l}0.098(-0.127 \text { to } \\
0.323)\end{array}$ \\
\hline Current smoking & 0.265 (0.201 to 0.329$)$ & 0.353 (0.278 to 0.428$)$ & $\begin{array}{l}0.049(-0.137 \text { to } \\
0.234)\end{array}$ \\
\hline $\mathrm{HbA} 1 \mathrm{c}^{*}$ & 0.973 (0.757 to 1.189$)$ & 0.765 (0.492 to 1.037$)$ & 1.485 (1.120 to 1.850$)$ \\
\hline Fasting glucose ${ }^{*}$ & 0.743 (0.617 to 0.869$)$ & 0.601 (0.436 to 0.766$)$ & 1.104 (0.900 to 1.308$)$ \\
\hline Total-c & 0.072 (0.046 to 0.099$)$ & $0.096(0.057$ to 0.135$)$ & 0.045 (0.009 to 0.082$)$ \\
\hline LDL-C & $0.052(0.021$ to 0.083$)$ & $0.042(-0.001$ to 0.086$)$ & $0.063(0.020$ to 0.106$)$ \\
\hline White blood cell & $0.096(0.081$ to 0.110$)$ & $0.111(0.091$ to 0.130$)$ & 0.089 (0.066 to 0.112$)$ \\
\hline hs-CRP* & $0.069(0.053$ to 0.085$)$ & 0.072 (0.049 to 0.095$)$ & 0.068 (0.044 to 0.092$)$ \\
\hline Homocysteine $^{*}$ & 0.147 (0.030 to 0.264$)$ & 0.278 (0.091 to 0.465$)$ & 0.235 (0.045 to 0.425$)$ \\
\hline VAT* & 0.438 (0.395 to 0.482$)$ & 0.516 (0.453 to 0.579$)$ & 0.458 (0.394 to 0.523$)$ \\
\hline $\mathrm{SAT}^{*}$ & 0.332 (0.276 to 0.387$)$ & 0.438 (0.360 to 0.516$)$ & 0.255 (0.163 to 0.346$)$ \\
\hline TAT $^{*}$ & 0.523 (0.465 to 0.580$)$ & 0.569 (0.494 to 0.644$)$ & 0.446 (0.355 to 0.536$)$ \\
\hline \multicolumn{4}{|c|}{$\begin{array}{l}\text { HbA1c = hemoglobin A1c, Total-c = total cholesterol, LDL-c = low-density lipoprotein cholesterol, hs- } \\
\text { CRP = high-sensitivity C-reactive protein, VAT = visceral adipose tissue, SAT = subcutaneous adipose } \\
\text { tissue, TAT = total adipose tissue, SBI = silent brain infarct }\end{array}$} \\
\hline
\end{tabular}




\begin{tabular}{|llll|}
\hline & Total & Male & Female \\
\hline SBI & $0.112(0.016$ to 0.208$)$ & $0.034(-0.104$ to 0.173$)$ & 0.198 (0.066 to 0.329) \\
\hline Number of SBI & $0.057(0.000$ to 0.114) & $0.002(-0.085$ to 0.090$)$ & $0.104(0.030$ to 0.178) \\
\hline $\begin{array}{l}\text { HbA1c = hemoglobin A1c, Total-c = total cholesterol, LDL-c = low-density lipoprotein cholesterol, hs- } \\
\text { CRP = high-sensitivity C-reactive protein, VAT = visceral adipose tissue, SAT = subcutaneous adipose } \\
\text { tissue, TAT = total adipose tissue, SBI = silent brain infarct }\end{array}$ & \\
\hline *These variables were transformed into a log scale. & \\
\hline
\end{tabular}

The reason why the direction of association between age, the most powerful risk factor for SBI, and VAI was apposite in male and female can be explained by the apposite change of anthropometric indices level as aging in both sex (Table 5). Male participants showed a decrease in anthropometric indices (e.g., BMI and SAT) as they grew older, while an increase was seen in females (e.g., BMI, WC, VAT, and TAT) (Table 5). 
Table 5

Difference of anthropometric indices according to age in male and female participants

\begin{tabular}{|c|c|c|c|c|}
\hline & $55>$ Age & $65>$ Age $\geq 55$ & Age $\geq 65$ & $P$ for trend \\
\hline Male & 639 & 573 & 188 & \\
\hline BMI & $24.70[23.13-26.42]$ & 24.34 [22.58-25.94] & 24.19 [22.06-25.87] & $<0.001$ \\
\hline WC & $89.0[84.0-93.0]$ & $88.5[83.0-93.5]$ & $89.3[84.0-94.0]$ & 0.695 \\
\hline VAT & 127.60 [91.01-167.11] & $127.92[91.51-165.42]$ & 139.80 [92.28-181.54] & 0.233 \\
\hline SAT & $\begin{array}{l}136.12[106.70- \\
173.49]\end{array}$ & $127.82[96.79-160.70]$ & $127.66[100.62-161.39]$ & 0.003 \\
\hline TAT & $\begin{array}{l}266.78[210.32- \\
333.56]\end{array}$ & $\begin{array}{l}258.88 \text { [199.97- } \\
322.87]\end{array}$ & $\begin{array}{l}271.36 \text { [202.36- } \\
342.20]\end{array}$ & 0.361 \\
\hline VAl & $1.44[0.87-2.21]$ & $1.21[0.80-1.87]$ & $1.08[0.76-1.85]$ & $<0.001$ \\
\hline Female & 512 & 527 & 157 & \\
\hline BMI & $23.03[21.06-24.76]$ & 23.45 [21.79-25.37] & 23.64 [21.74-25.65] & 0.001 \\
\hline WC & $80.3[75.0-85.8]$ & $84.0[79.0-89.0]$ & $85.5[80.0-91.5]$ & $<0.001$ \\
\hline VAT & 74.09 [53.01-98.62] & 91.58 [67.56-122.41] & 110.53 [78.66-155.74] & $<0.001$ \\
\hline SAT & $\begin{array}{l}176.49[138.85- \\
218.78]\end{array}$ & $\begin{array}{l}184.68 \text { [143.85- } \\
229.26]\end{array}$ & $182.81[139.66-227.81]$ & 0.128 \\
\hline TAT & $\begin{array}{l}255.61 \text { [197.56- } \\
316.11]\end{array}$ & $\begin{array}{l}277.46 \text { [226.26- } \\
348.43]\end{array}$ & 293.87 [235.23-370.34] & $<0.001$ \\
\hline VAl & $1.19[0.83-1.85]$ & $1.32[0.90-2.08]$ & $1.48[0.98-2.19]$ & $<0.001$ \\
\hline
\end{tabular}

\section{Discussion}

In this study, we found that high VAl level was associated with both SBI prevalence and burden in a neurologically healthy population, while VAT area was not. Our findings suggest that VAI which encompasses metabolic susceptibility caused by visceral adiposity is more relevant predictor for SBI than simple VAT quantity. These meaningful findings were found only in female participants, consistent with previous studies. $[13,17,18]$

Although the exact pathological mechanisms underlying the relationship between VAI and SBI is not clear. Several plausible mechanisms can be considered. First, this may be due to synergistic effects of well-known risk factors included in the VAl calculation formula.[8] High TG, low HDL cholesterol, and high WC are all well-known cerebrovascular risk factors.[19-21] Thus, the VAI developed from these 
combinations may be more strongly associated with SBI than for each individual risk factor. Second, the effects of metabolic comorbidities cannot be ignored. The aforementioned lipid profiles exhibited by high VAl are also called "atherogenic dyslipidemia", a common finding in visceral obesity, insulin resistance, and metabolic syndrome.[12, 22] Indeed, in both previous studies and our findings (Table 4), VAl has shown to be closely associated with metabolic diseases such as hypertension and diabetes, each of which is a major risk factor for SBI.[8-10,14,23] Third, endothelial dysfunction due to subclinical inflammation may be the main cause. Adipose tissue is not just a storage organ that actively releases various hormones or substances. [6] In particular, VAT tends to secrete more pro-inflammatory adipokines (e.g., IL-6, IL-8, TNF-a, and PAI-1) than SAT.[12, 23-25] Therefore, subclinical inflammation might be severe in patients with high VAI,[5] which mainly reflects the function of VAT. This could be partly confirmed by the close relationship between VAI and WBC, hs-CRP, homocysteine in Table 4. Endothelial dysfunction in small arteries/arterioles may cause their occlusion or block perivascular glymphatic drainage, resulting in SBI development.[15, 26] Lastly, high VAI can indicate an underlying higher atherosclerosis burden. Previous studies have shown that VAI is associated with intra- and extracranial atherosclerosis, $[3,5,13]$ probably due to the aforementioned atherogenic dyslipidemia or subclinical inflammation. Advanced atherosclerotic lesions can develop SBI with chronic diffuse hypoperfusion and extravasation of toxic metabolites into neural tissues.[15, 26]

Perhaps, the most interesting finding in this study is that even though VAI was created by adjusting for sex differences,[8] it is meaningful only in females. Previous studies investigating atherosclerosis or cardiovascular diseases have shown similar results, but the cause of these results is not clear.[13,17, 18] They speculate that the hormonal difference between males and females or differences in composition of VAT and SAT underlie these results.[17] Based on our findings, we propose a slightly different reason. Firstly, the relationship between age and VAI may affect this sexual difference. Age is the strongest risk factor for cerebrovascular disease, including SBI. As shown in Tables 4 and 5, there is no significant increase in VAT with age in male patients, but rather a negative relationship between VAI and age with decreasing SAT. On the other hand, as females get older, anthropometric indicators (e.g., WC, VAT, and TAT) increase markedly and VAl increases. As a result, in females, VAl also serves as an indicator of age and may have more pronounced results. In addition, females had a lower prevalence of metabolic disease, but association between metabolic disease and VAl was stronger than in males (Table 4 and Additional file 1: Table S1). In other words, visceral obesity is more likely to be involved in the development of potent risk factors such as hypertension and diabetes, and there are fewer other confounders that can influence VAl's impact on SBI. This may make VAI more influential in females.

In our study, VAI had a stronger predictive power on the prevalence of SBI than VAT. This may indicate that functional activity is more important than the amount of visceral fat, $[5,10,14]$ and is consistent with recent recognition that metabolic status is more important than the severity of obesity.[4]

There are several caveats to interpret our findings. First, the current study is a retrospective observational study. We included a relatively homogeneous and large population; however, the possibility of selection bias still remains. Second, due to the limitations of cross-sectional analysis, we could only prove the 
association, not causality. Further prospective studies are needed to confirm our results. Third, because we only included a healthy population, the prevalence of SBI and cardiovascular risk factors were relatively small. Therefore, the results of this study cannot be easily generalized and applied to clinical fields. However, despite the small number of outcome events, VAI and SBI showed a strong relationship.

\section{Conclusion}

In conclusion, we demonstrated that high VAI level is associated with SBI prevalence and burden in a neurologically healthy population, especially in females. VAl can be calculated from the results of simple laboratory examinations commonly used in the clinical fields, and its predictive power for SBI is superior to VAT in our data. Thus, our findings indicate that VAI could be used as a simple and convenient predictive marker for the prevalence and burden of SBI.

\section{Abbreviations}

VAT

visceral adipose tissue; SAT:subcutaneous adipose tissue; BMI:body mass index; WC:waist circumference; TG:triglyceride; HDL:high-density lipoprotein; VAl:visceral adipose index; SBI silent brain infarct; hs-CRP:high-sensitivity c-reactive protein; TR:repetition time; TE:echo time; TAT:total adipose tissue

\section{Declarations}

\section{Ethics approval and consent to participate:}

This study was approved by the Ethics Committee of Seoul National University Hospital and was carried out according to the guideline set out in the Declaration of Helsinki. Informed consent was waived from IRB due to the retrospective nature of the study.

\section{Consent for publication:}

Not applicable.

\section{Availability of data and materials:}

The datasets used and/or analyzed during the current study are available from the corresponding author on reasonable request.

\section{Competing interests:}

The authors declare that they have no competing interests. 


\section{Funding:}

There was no grant support for the present study.

\section{Authors' contributions:}

K.-W.N. and J.-H.P. designed the study. K.-W.N., H.-Y.J., HT.K., and S.-M.J. contributed to data acquisition. K.-W.N. performed statistical analysis. K.-W.N., H.-M.K., J.-H.P., HT.K., and S.-M.J. contributed to the discussion. K.-W.N. drafted the manuscript, and H.-M.K. and J.-H.P. edited the manuscript. All authors read and approved the final manuscript.

\section{Acknowledgements:}

None.

\section{References}

1. Hinnouho G-M, Czernichow S, Dugravot A, Batty GD, Kivimaki M, Singh-Manoux A. Metabolically healthy obesity and risk of mortality: does the definition of metabolic health matter? Diabetes Care. 2013;36(8):2294-300.

2. Bradshaw PT, Monda KL, Stevens J. Metabolic syndrome in healthy obese, overweight, and normal weight individuals: the Atherosclerosis Risk in Communities Study. Obesity. 2013;21(1):203-9.

3. Yang F, Wang G, Wang Z, Sun M, Cao M, Zhu Z, Fu Q, Mao J, Shi Y, Yang T. Visceral adiposity index may be a surrogate marker for the assessment of the effects of obesity on arterial stiffness. PloS one $2014,9(8)$.

4. Nam K-W, Kwon H-M, Jeong H-Y, Park J-H, Kwon H, Jeong S-M. Obesity without metabolic disorder and silent brain infarcts in aneurologically healthy population. International Journal of Obesity 2019:1-6.

5. Randrianarisoa E, Lehn-Stefan A, Hieronimus A, Rietig R, Fritsche A, Machann J, Balletshofer B, Häring H-U, Stefan N, Rittig K. Visceral adiposity index as an independent marker of subclinical atherosclerosis in individuals prone to diabetes mellitus. Journal of atherosclerosis and thrombosis 2019:47274.

6. Nam K-W, Kwon H, Kwon H-M, Park J-H, Jeong H-Y, Kim SH, Jeong S-M, Kim HJ, Hwang S-S. Abdominal fatness and cerebral white matter hyperintensity. Journal of the neurological sciences. 2019;404:52-7.

7. Alberti K, Eckel RH, Grundy SM, Zimmet PZ, Cleeman JI, Donato KA, Fruchart J-C, James WPT, Loria $\mathrm{CM}$, Smith SC Jr. Harmonizing the metabolic syndrome: a joint interim statement of the international diabetes federation task force on epidemiology and prevention; national heart, lung, and blood 
institute; American heart association; world heart federation; international atherosclerosis society; and international association for the study of obesity. Circulation. 2009;120(16):1640-5.

8. Amato MC, Giordano C, Galia M, Criscimanna A, Vitabile S, Midiri M, Galluzzo A. Visceral Adiposity Index: a reliable indicator of visceral fat function associated with cardiometabolic risk. Diabetes Care. 2010;33(4):920-2.

9. Borruel S, Molto JF, Alpanes M, Fernandez-Duran E, Alvarez-Blasco F, Luque-Ramirez M, EscobarMorreale HF. Surrogate markers of visceral adiposity in young adults: waist circumference and body mass index are more accurate than waist hip ratio, model of adipose distribution and visceral adiposity index. PloS one 2014, 9(12).

10. Amato MC, Giordano C, Pitrone M, Galluzzo A. Cut-off points of the visceral adiposity index (VAI) identifying a visceral adipose dysfunction associated with cardiometabolic risk in a Caucasian Sicilian population. Lipids Health Dis. 2011;10(1):183.

11. Han L, Fu K-I, Zhao J, Wang Z-h, Tang M-x, Wang J, Wang H, Zhang Y, Zhang W, Zhong M. Visceral adiposity index score indicated the severity of coronary heart disease in Chinese adults. Diabetol Metab Syndr. 2014;6(1):143.

12. Park H-J, Kim J, Park SE, Park C-Y, Lee W-Y, Oh K-W, Park S-W, Rhee E-J. Increased risk of subclinical atherosclerosis associated with high visceral adiposity index in apparently healthy Korean adults: the Kangbuk Samsung Health Study. Annals of medicine. 2016;48(6):410-6.

13. Li R, Li Q, Cui M, Ying Z, Li L, Zhong T, Huo Y, Xie P. Visceral adiposity index, lipid accumulation product and intracranial atherosclerotic stenosis in middle-aged and elderly Chinese. Scientific reports. 2017;7(1):1-9.

14. Dereziński T, Zozulińska-Ziółkiewicz D, Uruska A, Dąbrowski M: Visceral adiposity index as a useful tool for the assessment of cardiometabolic disease risk in women aged 65 to 74 . Diabetes/metabolism research and reviews 2018, 34(8):e3052.

15. Wardlaw JM, Smith EE, Biessels GJ, Cordonnier C, Fazekas F, Frayne R, Lindley RI, O'Brien T, Barkhof J, Benavente F. OR: Neuroimaging standards for research into small vessel disease and its contribution to ageing and neurodegeneration. Lancet Neurol. 2013;12(8):822-38.

16. Vermeer SE, Longstreth WT Jr, Koudstaal PJ. Silent brain infarcts: a systematic review. Lancet Neurol. 2007;6(7):611-9.

17. Nakagomi A, Sunami Y, Kawasaki Y, Fujisawa T, Kobayashi Y. Sex difference in the association between surrogate markers of insulin resistance and arterial stiffness. Journal of Diabetes and its Complications 2019:107442.

18. Mohammadreza B, Farzad H, Davoud K. Prognostic significance of the complex" visceral adiposity index" vs. simple anthropometric measures: Tehran lipid and glucose study. Cardiovascular diabetology. 2012;11(1):20.

19. Freiberg JJ, Tybjærg-Hansen A, Jensen JS, Nordestgaard BG. Nonfasting triglycerides and risk of ischemic stroke in the general population. Jama. 2008;300(18):2142-52. 
20. Furukawa Y, Kokubo Y, Okamura T, Watanabe M, Higashiyama A, Ono Y, Kawanishi K, Okayama A, Date $\mathrm{C}$. The relationship between waist circumference and the risk of stroke and myocardial infarction in a Japanese urban cohort: the Suita study. Stroke. 2010;41(3):550-3.

21. Wannamethee SG, Shaper AG, Ebrahim S. HDL-cholesterol, total cholesterol, and the risk of stroke in middle-aged British men. Stroke. 2000;31(8):1882-8.

22. Grundy SM. Small LDL, atherogenic dyslipidemia, and the metabolic syndrome. Circulation. 1997;95(1):1-4.

23. Ding Y, Gu D, Zhang Y, Han W, Liu H, Qu Q. Significantly increased visceral adiposity index in prehypertension. PLoS One 2015, 10(4).

24. Després JP. Is visceral obesity the cause of the metabolic syndrome? Annals of medicine. 2006;38(1):52-63.

25. Farb MG, Ganley-Leal L, Mott M, Liang Y, Ercan B, Widlansky ME, Bigornia SJ, Fiscale AJ, Apovian $\mathrm{CM}$, Carmine B. Arteriolar function in visceral adipose tissue is impaired in human obesity. Arterioscler Thromb Vasc Biol. 2012;32(2):467-73.

26. Pantoni L. Cerebral small vessel disease: from pathogenesis and clinical characteristics to therapeutic challenges. Lancet Neurol. 2010;9(7):689-701.

\section{Figures}

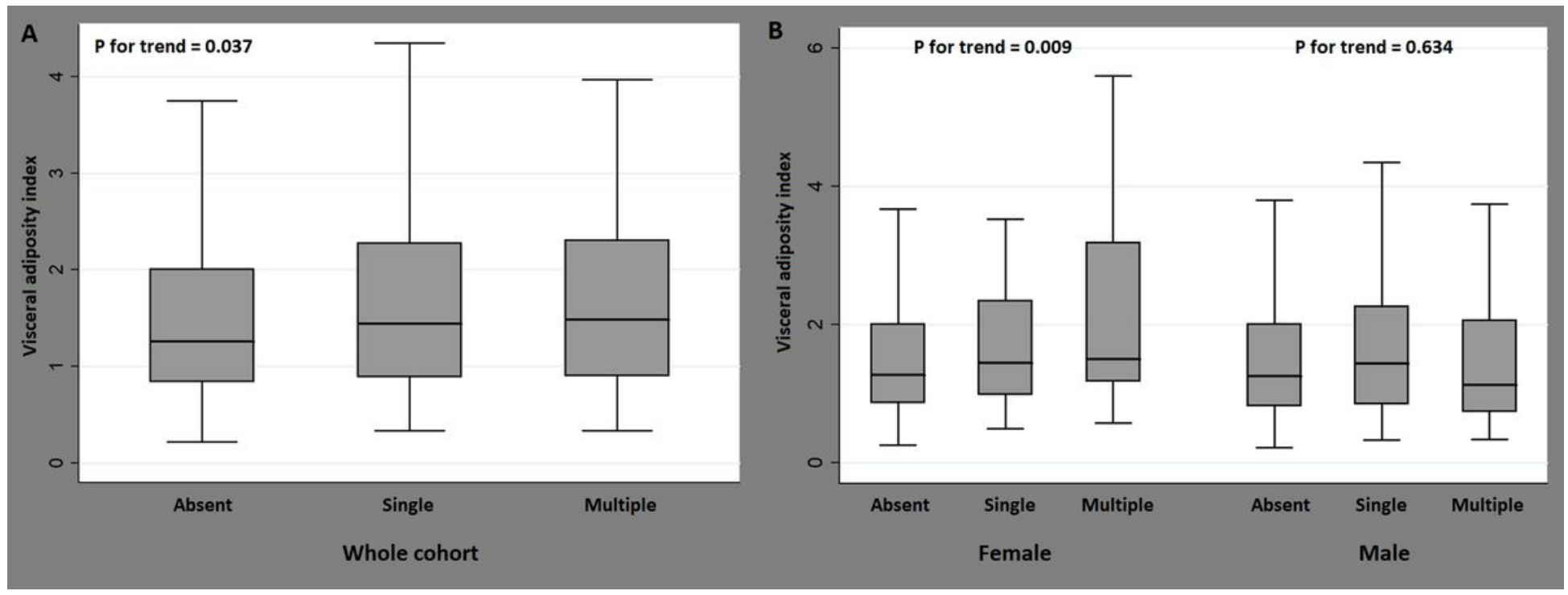

\section{Figure 1}

Distribution of median visceral adiposity index (VAI) according to the burden of silent brain infarct (SBI) Patients with multiple SBI lesions had a higher VAl as compared to those with absent or a single lesion in a dose-response manner ( $P$ for trend $=0.037$ ). This tendency was more pronounced in female participants $(P$ for trend $=0.009)$ and not in male participants $(P$ for trend $=0.643)$. 


\section{Supplementary Files}

This is a list of supplementary files associated with this preprint. Click to download.

- AdditionalFiles.docx 